\title{
ORGANO-METALLIC COMPOUNDS
}

$\mathrm{T}$ HE symposium entitled "Organo-Metallic Compounds", which was held in the University of Manchester on April 21, was one of the annual symposia organized jointly by the Chemical Society, the Institute of Petroleum, the Royal Institute of Chemistry and the Society of Chemical Industry. These symposia have become very popular of recent years, and the interest in this year's subject was evident from the attendance of about four hundred members and the liveliness of the discussion. Dr. R. E. Fairbairn and Dr. H. Gudgeon, of the Manchester and District Section of the Royal Institute of Chemistry, are to be congratulated on their arrangement of so successful a meeting. The highlight was the evening lecture by Prof. K. Ziegler, of the Max-Planck-Institut für Kohlenforschung, Mülheim, who described some of the recent advances in the chemistry of organo-aluminium compounds and their important industrial applications, which were discovered in his laboratory.

It was auspicious that this symposium should take place in Manchester, where the first professor of chemistry, E. Frankland, prepared the first organometallic compound, diethylzine, just over a hundred years ago. The meeting was opened by Prof. E. R. H. Jones, who was chairman of the morning session; Mr. G. Osgood took the chair in the afternoon, and Sir Robert Robinson in the evening. The subject of the symposium was introduced by Prof. G. E. Coates (University of Durham) with a review of some recent developments in the chemistry of organo-metallic compounds. Although there has been little progress in the elucidation of the structures of the chromium phenyls and lithium alkyls, the realization that the lighter elements tend to use all their low-energy orbitals in forming covalent compounds has helped considerably in the understanding of the chemistry of the organo-metallic compounds of the lighter metals of groups 2 and 3 in the Periodic Table. The utilization of all low-energy orbitals is accomplished by the polymerization of the simple molecules, for example, $\left(R_{2} \mathrm{~B} \Theta\right)_{n}$ and $\left(R_{3} \mathrm{Al}\right)_{2}$, or, if suitable donor substances are present, by the formation of coordination compounds, for example, $R_{3} \overrightarrow{\mathrm{Al}}-\stackrel{\mathrm{N}}{ } R_{3}$ or $\mathrm{K}\left[\mathrm{BPh}_{4}\right]$. Sometimes both methods are used together as in a series of compounds $\left(\mathrm{PMe}_{3}\right)_{2}\left(\mathrm{Me}_{2} \mathrm{Be}\right)_{m}$ formed by the reaction of $\mathrm{PMe}_{3}$ with $\left(\mathrm{Me}_{2} \mathrm{Be}\right)_{n}$. In an enclosed system the value of $m$ increases in a stepwise manner as the temperature is raised. The stabilities of the co-ordination compounds of the alkyls of the group 3 elements indicate that their acceptor properties increase from boron to aluminium, and then decrease regularly to thallium. Only thallium shows any evidence of $d_{\pi}-d_{\pi}$ bonding such as is found in the complex compounds of the platinum metals. The donor properties of the trimethyls of the group 5 elements in co-ordination to trimethylgallium decrease monotonously from trimethylamine to trimethylbismuthine.

The other extreme in structural type, when $d_{\pi}$ bonding by the metal is all-important, was next considered by Dr. J. Chatt (Akers Research Labor. atories, Imperial Chemical Industries, Ltd.), who discussed the structure of the olefin complexes with metallic salts. He described the structure of the
$\left[\mathrm{C}_{2} \mathrm{H}_{4} \mathrm{PtCl}_{3}\right]^{-}$ion in terms of atomic and molecular orbitals. No simple donation of $\pi$-electrons from the olefin to the metal can explain the properties of the stable olefin complexes. A structure was proposed in which the olefin-to-metal bond is a type of double bond. The $\sigma$-component of the co-ordinate bond is formed by donation of the $\pi$-electrons of the olefin to the metal atom, and the $\pi$-type component of the co-ordinate bond by the back donations of an electron pair from a $d$-orbital (or $d p$-hybrid orbital) of the metal atom into the anti-bonding $\pi$-molecular orbital of the olefin. It is significant that the only metals known to form stable olefin complexes have all their $d$-orbitals filled and are in low valency states, namely, $\mathrm{Cu}(\mathrm{I}), \operatorname{Pd}(\mathrm{II}), \mathrm{Ag}(\mathrm{I}), \mathrm{Pt}(\mathrm{II}), \mathrm{Hg}(\mathrm{II})$ and, recently added, $\mathrm{Rh}(\mathrm{I})$. Some of the more important properties of olefin complexes were described and shown to be consistent with the proposed structure.

Dr. F. G. Mann (University of Cambridge) concluded the morning session with a paper on new reactions of Grignard reagents and their mechanisms. It is known that many $\beta$-substituted alkylhalides, for example, $\mathrm{ROCH}_{2} \mathrm{CH}_{2} X$, react with magnesium to give ethylene, $\mathrm{Mg}(\mathrm{OR})_{2}$ and $\mathrm{Mg} X_{2}$, instead of a Grignard reagent. Dr. Mann has studied similar systems in which an aromatic nucleus is interposed between the $\mathrm{CH}_{2}$ groups. When the alkoxymethyl and chloromethyl groups are in $o$ - and $p$-positions to each other as in $0-$ and $p$-methoxymethylbenzyl chlorides, the alkoxyl and chloro groups are eliminated with the formation, in these examples, of $o$-xylylene (I) and $p$-xylylene respectively. These unstable products immediately polymerize. On the other hand, the $m$-isomer gives a normal Grignard reagent. o-Methoxymethylaniline with phenylmagnesium bromide gives a small proportion of polymerized o-quinomonomethaneimine (II) ; but the major product is $o$-benzylaniline. The $p$-isomer behaves similarly; but there is no reaction with the $m$-isomer. The mechanism of these and many related reactions was explained in terms of electron shifts. The reactions are valuable in organic syntheses, especially for the preparation of some simple $o$-substituted benzene derivatives.

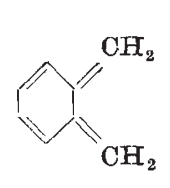

(I)

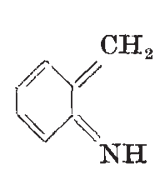

(II)

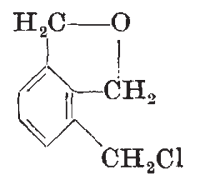

(III)
In the discussion which followed, Dr. G. Baddeley presented evidence that the alkoxyl group is eliminated only if the oxygen atom is free to turn out of the plane of the benzene ring; for example, the $o-\mathrm{CH}_{2}-\mathrm{O}$ bond is not broken by action of magnesium on (III). Prof. Ziegler also mentioned experience of compounds where elimination does not occur; for example, the reaction of magnesium with $(R \mathrm{O})_{2} \mathrm{CHCH}_{2} \mathrm{Br}$ gives the coupled product $\left((R \mathrm{O})_{2} \mathrm{CHCH}_{2}\right)_{2}$, provided $R$ is butyl or a higher alkyl group. Dr. E. A. Braude and Dr. N. R. Davies also took part in the discussion. 
In describing organo-iron compounds, Dr. M. C. Whiting (University of Manchester) discussed some interesting acetylene complexes derived from iron carbonyl, and the analytical difficulties encountered in establishing their composition. Two distinct types of compounds were described. The first was exemplified by the products of the reaction of phenyl. acetylene with iron carbonyl in the presence of nickel carbonyl. It is a yellow, crystalline and very stable substance $(\mathrm{PhC} \equiv \mathrm{C})_{2} \mathrm{Fe}(\mathrm{CO})_{4}$ isoelectronic with $\mathrm{Cr}(\mathrm{CO})_{8}$. The second series was obtained by reaction of acetylenic substances with iron carbonyl hydride. They are acids, for example, $\mathrm{H}_{2}\left[\mathrm{Fe}_{2}(\mathrm{CO})_{7} \mathrm{CH}_{3} \mathrm{C} \equiv \mathrm{CH}\right]$; but the structure of the anion is unknown. Probably it is similar to that of the uncharged cobalt complex $\left[\mathrm{Co}_{2}(\mathrm{CO})_{6} R \mathrm{C} \equiv \mathrm{C} R\right]$.

Dr. P. L. Pauson (University of Sheffield) gave a historical review of the development of the chemistry of biscyclopentadienyliron (ferrocene) and analogous compounds of the other transition metals. Of the more interesting reactions recently discovered is that of butyl-lithium to give dilithioferrocene, which has a lithium atom in each cyclopentadienyl ring, and those leading to the synthesis of phenylferrocenes up to octa-phenylferrocene. The carbonyl compounds $\mathrm{C}_{5} \mathrm{H}_{5} \mathrm{Fe}(\mathrm{CO})_{2} \mathrm{Br}$ and $\left(\mathrm{C}_{5} \mathrm{H}_{5}\right)_{2} \mathrm{Fe}_{2}(\mathrm{CO})_{4}$ were described. An $\mathrm{X}$-ray investigation indicates that the latter has the structure (IV) in which the $\mathrm{C}_{5} \mathrm{H}_{5}$ rings are perpendicular to the $\mathrm{Fe}-\mathrm{Fe}$ bond, and the terminal $\mathrm{CO}$ groups perpendicular to the plane of the bridging CO groups.

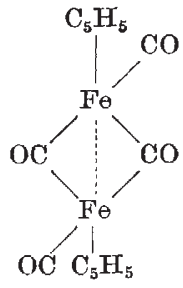

(IV)

Dr. D. Bryce-Smith (King's College, London) described his investigation of whether free radical intermediates occur in the Wurtz reaction. Wurtz reactions were carried out in the presence of $i$ sopropylbenzene. Many free radicals react with this compound to form 2:3-dimethyl-2:3-diphenylbutane by the following reactions:

$$
\begin{aligned}
& R .+\mathrm{PhCH}\left(\mathrm{CH}_{3}\right)_{2} \rightarrow R \mathrm{H}+\mathrm{PhC}\left(\mathrm{CH}_{3}\right)_{2} ; \\
& 2 \mathrm{PhC}\left(\mathrm{CH}_{3}\right)_{2} \rightarrow \mathrm{PhC}\left(\mathrm{CH}_{3}\right)_{2}-\mathrm{C}\left(\mathrm{CH}_{3}\right)_{2} \mathrm{Ph}
\end{aligned}
$$

The reaction of $n$-butyl iodide with sodium in isopropylbenzene gave, in addition to octane, about 1 per cent of $2: 3$-dimethyl-2:3-diphenylbutane, and the yield was similar when $n$-butylsodium was used in place of sodium metal. When lithium or $n$-butyl lithium reacted with $n$-butyl halides in isopropylbenzene, the yields of $2: 3$-dimethyl-2:3-diphenylbutane were 15-20 per cent. Octane was also formed. The fact that $2: 3$-dimethyl-2:3-diphenylbutane was not formed by the thermal decomposition of alkyllithium, -sodium and -potassium in isopropylbenzene solution indicates that free radicals were not produced, contrary to recent suggestions by Morton and Cluff ( $J$. Amer. Chem. Soc., 74, 4056 (1952) ; 75, 134 (1953)). On the other hand, $n$-butyl radicals, generated in isopropylbenzene by the photolysis of di-n-butylmercury, gave $2: 3$-dimethyl-2: 3-diphenylbutane in 50 per cent yield, but only traces of octane. Although free radicals are formed in Wurtz reactions, they probably contribute little to the coupling reaction and are produced in a secondary homolytic reaction between alkyl halide and alkali-metal alkyl.

The organic compounds of lithium and their use in synthesis were admirably reviewed by Dr. E. A. Braude (Imperial College of Science and Technology, London). They offer definite advantages over Grignard reagents. They are more reactive, and their reactions are more free from side reactions, possibly because of the absence of such equilibria as

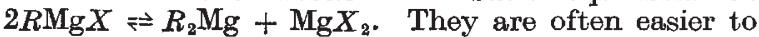
prepare, and many organic halides-for example, the vinyl compounds $R \mathrm{CH}=\mathrm{CHCl}-$ which do not give Grignard reagents, yield lithium compounds. The lithium compounds of the vinyl derivatives retain their configuration about the double bond; thus cis- $R \mathrm{CH}$ : $\mathrm{CHCl}$ yields cis- $R \mathrm{CH}$ : $\mathrm{CHLi}$. Dr. Braude also described numerous interesting syntheses in the aryl and heterocyclic series of organic compounds where the specific properties of lithium compounds are of especial importance.

It is not possible in the small space available to do justice to Prof. Ziegler's brilliant exposition of his recent researches into the properties of the alkyls of the lighter metals. $\mathrm{He}$ first described the pyrolysis of the methyl derivatives of lithium, magnesium and aluminium, then a new series of complex salts formed by aluminium alkyls and finally the use of aluminium alkyls as catalysts in the controlled polymerization of olefins.

'The pyrolysis of the heavy-metal alkyls usually gives free alkyl radicals, and of the lighter-metal alkyls, olefins and metal hydrides. The above methyls decompose, however, in neither of those ways. Methane is always a product of the pyrolysis, and in the case of trimethylaluminium a residue of $\mathrm{Al}_{4} \mathrm{C}_{3}$ remains. Lithium and magnesium methyls yield acetylides ; for example, $2 \mathrm{LiCH}_{3} \rightarrow \mathrm{CH}_{4}+$ $\mathrm{Li}_{2} \mathrm{CH}_{2}$, and then at higher temperature $3 \mathrm{Li}_{2} \mathrm{CH}_{2} \rightarrow$ $\mathrm{Li}_{2} \mathrm{C}_{2}+2 \mathrm{LiH}+2 \mathrm{Li}+\mathrm{CH}_{4}$. Pyrolysis of such complexes as $\mathrm{LiAlM}_{4}$ give mixed carbides, for example, LiAlC.

Four types of complex salts derived from aluminium alkyls were described: $\operatorname{Mg}\left[\mathrm{Al} R_{4}\right]_{2} ; R \mathrm{Mg}\left[\mathrm{Al} R_{4}\right]$; $\mathrm{Na}\left[\mathrm{Al} R_{2} \mathrm{~F}_{2}\right]$; and $\mathrm{Na}\left[\mathrm{Al} R_{3} \mathrm{~F}\right]$. Salts of the fourth type containing other halogens are stable only in the presence of the larger cations. The first are true salts; but the second do not conduct electricity and may be distilled in high vacuum. The third type, obtained from $R_{2} \mathrm{AlCl}$ and $\mathrm{NaF}$, decomposes on pyrolysis to give $R_{3} \mathrm{Al}+\mathrm{Na}_{3} \mathrm{AlF}_{6}$, and so provides a method of converting $R_{2} \mathrm{AlCl}$ into $R_{3} \mathrm{Al}$.

In the polymerization of ethylene under pressure at $100-110^{\circ} \mathrm{C}$. there are two stages: the growth reaction, al $\left(\mathrm{CH}_{2}\right)_{n} \mathrm{CH}_{3}+\mathrm{C}_{2} \mathrm{H}_{4} \rightarrow \operatorname{al}\left(\mathrm{CH}_{2}\right)_{n+2} \mathrm{CH}_{3}$; and the displacement reaction, $\operatorname{al}\left(\mathrm{CH}_{2}\right)_{n} \mathrm{CH}_{3}+\mathrm{C}_{2} \mathrm{H}_{4} \rightarrow$ $\mathrm{alCH}_{2} \mathrm{CH}_{3}+\mathrm{CH}_{2}=\mathrm{CH}\left(\mathrm{CH}_{2}\right)_{n-2} \mathrm{CH}_{3} \quad\left(\mathrm{al}=\frac{1}{8} \mathrm{Al}\right)$. The relative rates of these two reactions determine the length of the polymer chain. The displacement reaction is greatly accelerated by traces of colloidal nickel, poisoning of which is inhibited by phenylacetylene. In its presence smooth conversion of ethylene to butene is achieved. Prof. Ziegler also described schemes for the conversion of ethylene to higher $n$-alk-1-enes, and for obtaining $n$-alcohols from ethylene by oxidation and hydrolysis of the products of the growth reaction. His lecture was followed by an interesting discussion.
J. CHatT 